\title{
Safety of Nonoperative Management After Acute Diverticulitis
}

\author{
Javier Suarez Alecha, Sonia Amoza Pais, Xavi Batlle Marin, Begoña Oronoz Martinez, \\ Enrique Balen Ribera, Concepción Yarnoz Irazabal \\ Departament of Surgery, Unit of Coloproctology, Complejo Hospitalario de Navarra, Pamplona, Spain
}

\begin{abstract}
Purpose: The role of surgery in the management of diverticular disease after an episode of acute diverticulitis (AD) managed in a conservative form is evolving. Age, number of episodes of $\mathrm{AD}$, type of episode, and symptoms after the episodes are factors related to the need for elective surgery. The aim of this study is to evaluate the safety of conservative management and the risk factors for emergency surgery after a first episode of AD managed without surgery.

Methods: We retrospectively evaluated 405 patients diagnosed as having had a first episode of AD. Sixty-nine patients underwent emergency surgery on the first admission, and 69 patients had an elective operation in the follow-up (group A). The remaining 267 patients were managed initially without surgery (group B). Thirteen of these 267 patients needed a further urgent surgical procedure. Factors involved in the decision of elective surgery and the probability of emergency surgery after the first episode of $\mathrm{AD}$ managed without surgery were evaluated in relation to demographic factors, risk factors, presence of recurrences, and type of the first episode.

Results: Patients' mean age was 62.7 years, 71 were aged less than 51, and 151 were males. The mean follow-up for patients with nonoperative management was 91.2 months. An elective operation was performed in 69 patients. Compared to patients in group B, those in group A more frequently had a first episode of complicated acute diverticulitis (CAD) (37.1\% vs. 16.4\%; $\mathrm{P}=0.000)$ and were more likely to be smokers ( $46.3 \%$ vs. $19.3 \% ; \mathrm{P}=0.000)$ and to suffer more than one episode of $\mathrm{AD}(42 \%$ vs. $26.9 \%$; $\mathrm{P}=0.027)$. Nonoperative management was chosen for 267 patients, but 13 patients needed an emergency operation later. In the multivariate analysis, we found a significant relation between the presence of CAD in the first episode and the need for emergency surgery. There were no differences in surgical mortality between the patients in the two groups, but patients treated with elective surgery had a higher rate of stoma than patients treated non-operatively $(7.2 \%$ vs. $1.4 \% ; \mathrm{P}=$ $0.028)$; this difference was not observed in the subgroup of patients with $\mathrm{CAD}(15.3 \%$ vs. $6.8 \% ; \mathrm{P}=0.458)$.

Conclusion: After an episode of $\mathrm{AD}$, nonoperative management is safe because fewer than $5 \%$ of patients will need an emergent procedure in a subsequent attack of $\mathrm{AD}$. A first episode of CAD is the only risk factor for emergency surgery in patients managed conservatively.
\end{abstract}

Keywords: Complicated acute diverticulitis; Acute diverticulitis surgery; Colonic diverticulitis

Received: April 5, 2014 - Accepted: July 30, 2014

Correspondence to: Javier Suarez Alecha, M.D.

Departament of Surgery, Complejo Hospitalario de Navarra C/Irunlarrea № 3, 31008, Pamplona-Navarra, Spain

Tel: +34-848-422179, Fax: +34-848-422303

E-mail:fj.suarez.alecha@cfnavarra.es

(C) 2014 The Korean Society of Coloproctology

This is an open-access article distributed under the terms of the Creative Commons Attribution NonCommercial License (http://creativecommons.org/licenses/by-nc/3.0) which permits unrestricted noncommercial use, distribution, and reproduction in any medium, provided the original work is properly cited.

\section{INTRODUCTION}

Diverticular disease is a common disorder of the colon in the developed world [1]. Many patients with diverticulosis remain asymptomatic, but acute diverticulitis $(\mathrm{AD})$ is one of the commonest complications. Patients who have developed a first episode of $\mathrm{AD}$ can remain asymptomatic for life, but are at risk of a new episode of $\mathrm{AD}$, with some of them needing emergency surgery due to complicated acute diverticulitis (CAD). In recent years, the indications for surgery after an episode of $\mathrm{AD}$ have been becoming more and more restrictive. Thus, the aim of this study is to evalu- 
ate the safety of conservative management and the risk factors for emergency surgery after a first episode of $\mathrm{AD}$ that was managed conservatively.

\section{METHODS}

The medical records of patients who had been admitted to institution (Department of Surgery, Complejo Hospitalario de Navarra, Pamplona, Spain) and discharged with a diagnosis of $\mathrm{AD}$ from 1 January 1999 to 31 December of 2011 were reviewed. Patients were included in the study if they had a clinical and radiological diagnosis of left-sided AD on computed tomography (CT) or ultrasonography and a posterior confirmation of diverticula with an $\mathrm{x}$-ray contrast enema or colonoscopy. If a colon cancer or inflammatory bowel disease was found or diverticula were not demonstrated, patients were not considered for the study.

A surgical procedure was considered urgent if it was performed after an urgent admission and before discharge. In other cases, the procedure was considered elective. Conservative management is referred to patients in whom an elective surgical procedure was not proposed after a first attack of $\mathrm{AD}$.

Age, gender, risk factors, such as smoking tobacco, chronic renal failure (CRF), nonsteroidal anti-inflammatory drugs (NSAIDs) or corticosteroid use, diabetes mellitus (DM), immunodeficiency, body mass index (BMI), type of $\mathrm{AD}$ in the first episode (uncomplicated acute diverticulitis [UAD] or CAD), presence of subsequent episodes of $\mathrm{AD}$, posterior elective or urgent surgery, type and mortality of surgery, were recorded for all patients. Patients were divided by BMI into groups of less than or equal to $30 \mathrm{~kg} / \mathrm{m}^{2}$ and greater than $30 \mathrm{~kg} / \mathrm{m}^{2}$ and by age into groups of less than or equal to 50 years and greater than 50 years based on the results of previous studies. Complicated diverticulitis was defined as $\mathrm{AD}$ followed by colonic perforation, abscess, intestinal obstruction, stricture, or fistula. A recurrent episode was defined based on a need for a patient to be admitted to the hospital due to $\mathrm{AD}$ or on the evaluation in the Emergency Department. Major morbidity was defined as a complication with grade 3 to 5 in Clavien-Dindo classification.

With respect to the indications for elective surgery, we considered the preponderant motive for surgery though more than one motive might be present in a patient (e.g., a patient could suffer recurrent attacks and persistent symptoms). CAD, as an indication for elective surgery, is noted for patients in whom surgery was indicated after recovery from an episode of CAD. A phone interview or mail questionnaire was done to rule out surgery or admission to any other hospital.

The total number of patients evaluated after a first episode of $\mathrm{AD}$ was 405:139 (34.3\%) had an episode of CAD, and 266 had an episode of UAD. Sixty-nine patients with CAD underwent an emergency operation during the first admission and were excluded from the study. Thus, the analysis was involved 336 patients. Of these 336 patients, 266 (79.2\%) were classified as having UAD and
70 (20.7\%) as having CAD. Also, of these 336 patients, 69 underwent elective surgery (group A), and 267 patients were managed conservatively (group B). Patients in group B were treated with dietary modifications and oral or intravenous broad-spectrum antibiotics +/- percutaneous drainage. Metronidazole ( $1.5 \mathrm{~g} / 24$ hours) plus Cefotaxime ( $1 \mathrm{~g} / 8$ hours) is the standard first-line treatment in our institution. Thirteen of the 267 patients who were treated conservatively needed further emergency surgery.

The decision to perform elective surgery and the assessment of the risk of emergency surgery after the first episode of $\mathrm{AD}$ that had been managed without surgery were evaluated in terms of demographic factors, risk factors, presence of recurrences, and type of the first episode (UAD or CAD). The study was approved by the research Ethics Committee of the Complejo Hospitalario de Navarra, Pamplona.

Categorical variables were compared using the chi-square test and Fisher exact test when appropriate. A univariate binary logistic regression analysis was used to evaluate the risk of emergency surgery. Independent significant predictors from the univariate analysis were further evaluated by using a multivariable logistic regression analysis model and SPSS ver. 17.0 (SPSS Inc., Chicago, IL, USA). Statistical significance was defined as $\mathrm{P} \leq 0.05$.

\section{RESULTS}

The mean age was 62.7 years (range, 25 to 96 years), 71 (21\%) were aged less than 51 years at first admission, and 151 (44.8\%) were males. The mean follow-up for patients managed conservatively 91.2 months.

The flowchart in Fig. 1 shows the evolution of patients after a first diagnosis of $\mathrm{AD}$. An elective surgery was performed in 69 patients: 43 cases after an episode of UAD and 26 after an episode of CAD

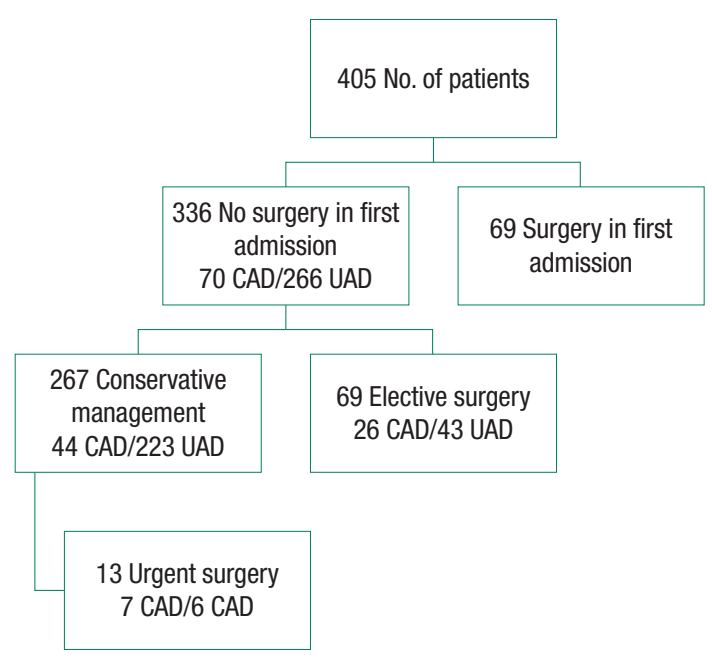

Fig. 1. Evolution of the patients after a first diagnosis of acute diverticulitis. CAD, complicated acute diverticulitis; UAD, uncomplicated acute diverticulitis. 
(group A). Twenty-nine patients suffered more than one episode of AD; 59 were classified as Hinchey I and 10 as Hinchey II. A conservative management was chosen for 267 patients (group B). These patients were treated with oral or intravenous broad-spectrum antibiotics; six patients needed percutaneous drainage of ab-

Table 1. Comparison between patients managed with and without elective surgery

\begin{tabular}{|c|c|c|c|}
\hline Variable & $\begin{array}{l}\text { Elective surgery } \\
\qquad(n=69)\end{array}$ & $\begin{array}{l}\text { No elective surgery } \\
\qquad(n=267)\end{array}$ & P-value \\
\hline Age (yr) & & & 0.413 \\
\hline$<50$ & $17(24.6)$ & $54(20.2)$ & \\
\hline$\geq 50$ & $52(75.4)$ & $213(79.8)$ & \\
\hline Gender & & & 0.077 \\
\hline Male & $38(55.1)$ & $113(42.3)$ & \\
\hline Female & $31(44.9)$ & $154(57.7)$ & \\
\hline Body mass index $\left(\mathrm{kg} / \mathrm{m}^{2}\right)$ & & & 0.187 \\
\hline$\leq 29$ & $44(63.8)$ & $121(45.3)$ & \\
\hline$\geq 30$ & $20(29.0)$ & 85 (31.9) & \\
\hline Unknown & $5(7.2)$ & $61(22.8)$ & \\
\hline First episode & & & 0.000 \\
\hline UAD & $43(62.3)$ & $223(83.5)$ & \\
\hline CAD & $26(37.7)$ & $44(16.5)$ & \\
\hline NSAID/steroid ${ }^{a}$ & & & 0.089 \\
\hline Yes & $1(1.4)$ & $19(7.1)$ & \\
\hline No & $68(98.6)$ & $248(92.9)$ & \\
\hline Chronic renal failure ${ }^{\mathrm{a}}$ & & & 1.000 \\
\hline Yes & $2(2.9)$ & $9(3.4)$ & \\
\hline No & 67 (97.1) & $258(96.6)$ & \\
\hline Diabetes mellitus $^{\mathrm{a}}$ & & & 0.620 \\
\hline No & $4(5.7)$ & $23(8.6)$ & \\
\hline Yes & 65 (94.2) & $244(91.4)$ & \\
\hline Tobacco & & & 0.000 \\
\hline Yes & $32(46.4)$ & $53(19.6)$ & \\
\hline No & 37 (53.6) & $209(78.3)$ & \\
\hline Unknown & $0(0)$ & $5(1.9)$ & \\
\hline Rheumatologic disease ${ }^{\mathrm{a}}$ & & & 0.058 \\
\hline Yes & $2(2.9)$ & 27 (10.1) & \\
\hline No & $67(97.1)$ & $240(89.9)$ & \\
\hline Recurrences & & & 0.027 \\
\hline Yes & $29(42.0)$ & $72(27.0)$ & \\
\hline No & $40(58.0)$ & $195(73.0)$ & \\
\hline
\end{tabular}

Values are presented as number (\%).

UAD, uncomplicated acute diverticulitis; CAD, complicated acute diverticulitis; NSAID, nonsteroidal anti-inflammatory drug.

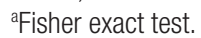

scesses. The characteristics of the patients in both groups are shown in Table 1.

The reasons for elective surgery were recurrent attacks in $30 \mathrm{pa}-$ tients (43.4\%), persistent symptoms in 27 (39.1\%), appearance of fistulae in $6(8.7 \%)$, and CAD in $6(8.7 \%)$. Compared to patients in group $\mathrm{B}$, those in group $\mathrm{A}$ had a high rate $\mathrm{CAD}$ in the first episode $(37.1 \%$ vs. $16.4 \%, P=0.000)$, were smokers $(46.3 \%$ vs. $19.3 \%$, $\mathrm{P}=0.000)$ and had suffered more than one episode of $\mathrm{AD}(41.4 \%$ vs. $17 \%, \mathrm{P}=0.027)$. There were no differences regarding $\mathrm{BMI}$, use of NSAIDs or corticosteroids, DM, CRF or immunodeficiency between the two groups.

After elective surgery, one patient died (1.4\%), nine patients suffered a major morbidity (12.8\%), and five stomas were created (7.1\%) (1 colostomy and 4 loop ileostomies). Of the 267 patients in group B, 13 (4.8\%) underwent an emergency operation during follow-up due to peritonitis (5 cases), intestinal obstruction (4 cases), abscess ( 3 cases) and failure of medical treatment ( 1 case). Four stomas were created (1.4\%) (4 colostomies), major morbidity was evidenced in 3 cases (1.1\%), and death occurred in 1 case (0.3\%). There were no differences in surgical mortality $(1.3 \%$ vs. $0.3 \%, \mathrm{P}=$ 0.379 ) between the two groups, but patients in group A had a higher rate of stoma creation $(7.1 \%$ vs. $1.4 \%, \mathrm{P}=0.028)$ and morbidity $(12.8 \%$ vs. $1.1 \%, \mathrm{P}=0.000)$ than the patients in group $\mathrm{B}$.

In the subgroup of patients with a first episode of CAD, 26 patients underwent an elective procedure, and 44 received nonoperative management. After the elective procedure, no deaths were reported, 4 patients (15.3\%) had a major morbidity, and 4 stomas were created. After nonoperative management, 7 patients needed an emergent surgical procedure, and 1 patient died (2.2\%), 2 patients suffered a major morbidity (4.5\%), and 3 stomas were created $(6.8 \%)$. There were no differences in the mortality, morbidity or stoma-creation rates between the two groups (Table 2).

Regarding the 13 patients who had emergency surgery, in the univariate analysis, we found a statistically significant relation between the need for emergency surgery after a first episode of $\mathrm{AD}$

Table 2. Comparison of rates of stoma creation, morbidity and mortality between patients treated with elective surgery and patients with nonoperative management

\begin{tabular}{lccc}
\hline Variable & Elective surgery & No elective surgery & P-value \\
\hline Complete group & 69 & 267 & \\
\hline Stoma rate & $5(7.2)$ & $4(1.5)$ & 0.028 \\
Morbidity & $9(13.0)$ & $3(1.1)$ & 0.000 \\
\hline Mortality & $1(1.4)$ & $1(0.4)$ & 0.379 \\
CAD & 26 & 44 & \\
Stoma rate & $4(15.4)$ & $3(6.8)$ & 0.458 \\
Morbidity & $4(15.4)$ & $2(4.5)$ & 0.261 \\
Mortality & $0(0)$ & $1(2.3)$ & 1.000 \\
\hline
\end{tabular}

Values are presented as number (\%).

$\mathrm{CAD}$, complicated acute diverticulitis. 
Table 3. Results of the univariate and the multivariate logistic regression analyses of the risk factors for emergency surgery

\begin{tabular}{|c|c|c|c|c|c|}
\hline Variable & №. (\%) & Univariate analysis & P-value & Multivariate analysis & P-value \\
\hline \multicolumn{6}{|l|}{ Type of AD } \\
\hline CAD & $7(15.9)$ & 4.87 (1.55-15.29) & 0.007 & $4.25(0.72-25.28)$ & 0.016 \\
\hline UAD & $6(2.6)$ & & & & \\
\hline \multicolumn{6}{|l|}{ Age (yr) } \\
\hline$<50$ & $12(5.6)$ & $0.31(0.40-2.48)$ & 0.316 & & \\
\hline$\geq 50$ & $1(1.8)$ & & & & \\
\hline \multicolumn{6}{|l|}{ Gender } \\
\hline Female & $10(6.4)$ & $0.39(0.11-1.46)$ & 0.163 & & \\
\hline Male & $3(2.6)$ & & & & \\
\hline \multicolumn{6}{|c|}{ Body mass index $\left(\mathrm{kg} / \mathrm{m}^{2}\right)$} \\
\hline$\geq 30$ & $6(7.0)$ & $0.64(0.07-5.48)$ & 0.686 & & \\
\hline$\leq 29$ & $1(0.8)$ & & & & \\
\hline \multicolumn{6}{|c|}{ NSAID/steroid } \\
\hline No & $13(4.8)$ & 0 & 0.998 & & \\
\hline Yes & $0(0)$ & & & & \\
\hline \multicolumn{6}{|c|}{ Chronic renal failure } \\
\hline Yes & $2(22.2)$ & $6.41(1.19-34.5)$ & 0.030 & & \\
\hline No & $11(4.2)$ & & & & \\
\hline \multicolumn{6}{|c|}{ Diabetes mellitus } \\
\hline Yes & $3(13.0)$ & 3.51 (0.89-13.79) & 0.072 & & \\
\hline No & $10(4.1)$ & & & & \\
\hline \multicolumn{6}{|l|}{ Tobacco } \\
\hline No & $11(5.2)$ & $1.41(0.30-6.59)$ & 0.657 & & \\
\hline Yes & $2(3.7)$ & & & & \\
\hline \multicolumn{6}{|c|}{ Rheumatologic disease } \\
\hline No & $12(5.0)$ & $1.36(0.17-10.95)$ & 0.768 & & \\
\hline Yes & $1(3.7)$ & & & & \\
\hline \multicolumn{6}{|c|}{ Recurrences } \\
\hline Yes & $6(8.2)$ & $0.79(0.23-2.65)$ & 0.703 & & \\
\hline No & $6(3.07)$ & & & & \\
\hline
\end{tabular}

Values are presented as odds ratio (95\% confidence interval) unless otherwise indicated.

AD, acute diverticulitis; CAD, complicated acute diverticulitis; UAD, uncomplicated acute diverticulitis; NSAID, nonsteroidal anti-inflammatory drug.

managed without elective surgery and (1) the presence of CRF (odds ratio [OR], 6.41; 95\% confidence interval [CI], 1.19-34.5; $\mathrm{P}$ $=0.030)$ and $(2)$ the type of the first episode of $\mathrm{AD}(\mathrm{OR}, 4.87$; $95 \% \mathrm{CI}, 1.55-15.2 ; \mathrm{P}=0.007)$. In the multivariate analysis, only the type of the first episode remained significant (Table 3 ).

\section{DISCUSSION}

Diverticular disease is a common disorder in Western countries. Although the majority of patients with colonic diverticula remain asymptomatic, episodes of $\mathrm{AD}$ have been reported in 10\%-25\% of patients [1,2]. On the basis of CT findings, Ambrosetti et al. [3] classified $\mathrm{AD}$ as moderate diverticulitis and as severe diverticulitis when an abscess, free extraluminal gas, or contrast extravasation was found. In our study, the presence of colonic perforation, abscess, intestinal obstruction, stricture, or fistula was considered as CAD. In our experience, $34.2 \%$ of patients suffered a first episode of CAD, which is in agreement with previous reports; in a retrospective analysis of over 502 patients, Eglinton et al. [4] found that $32.8 \%$ of the patients had suffered a first episode of CAD. 
Natural history of $\mathrm{AD}$ is unclear, and the role of prophylactic surgery following a conservatively managed episode of $\mathrm{AD}$ is controversial. Prevention of recurrent acute episodes and the need for urgent surgery are some of the main reasons for elective surgery following AD. Morbidity associated with elective surgery and the possibility of recurrence of $\mathrm{AD}$ following elective surgery should also be considered.

\section{Elective surgery}

In our study, 69 of 336 patients (20.5\%) managed without surgery in the first episode of $\mathrm{AD}, 43$ following an episode of UAD (16.4\%), and 26 after CAD (37.1\%) underwent posterior elective surgery. Dharmarajan et al. [5] reported very similar data: $48 \%$ of elective resections after an aggressive protocol of conservative management of CAD.

In recent years, the indications for elective surgery after a first episode of $\mathrm{AD}$ managed without surgery are becoming more and more restrictive. For example, the American Society of Colon \& Rectal Surgeons, as published by Rafferty et al. [6] in 2006, recommend an elective sigmoid colectomy after recovery from $\mathrm{AD}$ based on the individual patient's condition (age, general medical condition, number and severity of attacks, and persistence of symptoms), rather than on the number of attacks of UAD as an overriding factor in the decision to perform surgery. Nevertheless, in our study, elective surgery was indicated more frequently in patients with recurrent attacks ( $42 \%$ vs. $26.9 \% ; \mathrm{P}=0.018$ ). This result may have been influenced by practice parameters that recommend elective resection after two episodes of diverticulitis to reduce morbidity and mortality [7]. The presence of persistent symptoms was the other preponderant indication for elective surgery.

The need for an elective colectomy after recovery from $\mathrm{AD}$ in patients younger than 50 years of age remains controversial. Because of their longer life span, these patients have a higher cumulative risk of recurrent attacks. Some reports show a higher rate of complications among young patients compared to older patients [8], but Guzzo and Hyman [9] found only a $0.5 \%$ rate of subsequent diverticular perforation in medically-managed young patients with sigmoid diverticulitis. In a recent analysis, patients 45 years of age or younger had not differences in cumulative recurrence of DA compared to patients 46-70 years of age and to patients older than 70 years of age [10]. In our study, younger patients did not have a higher rate of elective surgery.

An elective colectomy has been generally performed after an episode of CAD managed nonoperatively. Kaiser et al. [11] found a $13 \%$ recurrence rate for mild cases compared to $41.2 \%$ for patients with a pelvic abscess that had been treated conservatively, and Hall et al. [12] showed that patients with a retroperitoneal abscess were at higher risk for recurrent disease. In our experience, a higher rate of $\mathrm{CAD}$ was present in group $\mathrm{A}$ than in group $\mathrm{B}$ (37.6\% vs. $16.4 \% ; \mathrm{P}=0.000$ ). In six patients elective surgery was indicated immediately after recovery from an episode of CAD.

Some studies have shown relations between BMI and an in- creased risk of $\mathrm{AD}$ [13], recurrent diverticulitis, and CAD [14]. Similarly, some authors have related smoking tobacco to the rate of perforations and postoperative recurrent attacks of $\mathrm{AD}$ [15]. Although these factors were not actively considered when proposing elective surgery in our study, related relation was found between tobacco consumption and an elective procedure. Our present trend is towards an individualized selection of patients for elective surgery after a first episode of $\mathrm{AD}$ that had been managed conservatively.

\section{Emergent surgery after conservative management}

This study provides natural history data from a cohort of patients with $\mathrm{AD}$ initially managed without surgery. Thirteen of those 267 patients $(4.8 \%)$ needed a further emergency operation. The presence of CRF and the type of the first episode of $\mathrm{AD}$ were related to the need for urgent surgery in the univariate analysis. Only a first episode of CAD was a risk factor for the need for emergent surgery in the multivariate analysis.

The data on recurrent attacks and the need for emergent surgery are controversial. Anaya and Flum [16] concluded that the risk of emergency surgery increases with increasing number of recurrent attacks. Nevertheless, Ritz et al. [17] found that the risk of free perforation decreased with increasing number of previous episodes of AD. They reported a risk of $5.5 \%$ for a colectomy or a colostomy in patients with recurrent $\mathrm{AD}$. Data on recurrences should be observed with caution because some episodes can be managed by a general practitioner or by patient himself without hospital admission. In our experience, the presence of recurrent attacks has not been related to a significant risk of emergent surgery.

The relation between CRF and the need for acute surgery has been described previously. Klarenbeek et al. [18] found that CRF was a risk factor for perforation in 88 patients with recurrent $\mathrm{AD}$. In our study, patients with CRF initially managed without surgery had an increased risk of emergency surgery, but that significance was not maintained in the multivariate analysis.

Although nonoperative management has been suggested after an episode of CAD [19], an elective colon resection has been advised after an episode of CAD. In our experience, $15.9 \%$ of the patients diagnosed as having $\mathrm{CAD}$ and managed without elective surgery needed an emergent surgical procedure, and this rate of emergency surgery was 5.5 times higher than that in patients diagnosed as having an episode of UAD, being the only significant risk factor for emergent surgery.

Only 37 of the 139 patients initially diagnosed as having a first episode of CAD (26.6\%) did not undergo a surgical procedure. These figures are quite similar to those reported by Dharmarajan et al. [5]. They managed without urgent or elective surgery 49 of 136 patients diagnosed as having CAD. Nevertheless, because $84 \%$ of the patients with CAD who are managed conservatively do not need a surgical procedure, we think that conservative management may be indicated in selected cases. 


\section{Benefit of elective surgery}

Interestingly, elective surgery had no protective effect for stoma creation, surgical morbidity, or death compared to nonoperative management. In fact, a higher rate of stoma formation was found after elective surgery than after emergency surgery because four temporal ileostomies were raised in elective surgery due to poor local conditions at the moment of colorectal anastomosis $(7.2 \%$ vs. $1.4 \%, \mathrm{P}=0.028)$. There were no differences between the subgroups of patients with $\mathrm{CAD}(15.3 \%$ vs. $6.8 \%, \mathrm{P}=0.458)$ (Table 2$)$. A similar stoma rate of $13.3 \%$ was reported by Dharmarajan et al. [5] in elective surgery after an episode of CAD, although in their report, a colostomy was performed more frequently than an ileostomy.

\section{Limitations}

Our study has some obvious limitations. First, it is a retrospective study, and the selection for elective surgery, based in more recent reports, has been changing during the period of the study. Second, analysis of recurrences might be difficult because some episodes have been managed by a general practitioner or the patient himself. Moreover, the differentiation between recurrent attacks and persistent symptoms may sometimes be difficult. However, this study is useful because it provides information about how patients progress and the rate of emergency surgery after conservative management of $\mathrm{AD}$.

In conclusion, this study confirms that nonoperative management of $\mathrm{AD}$ is safe, even after an episode of CAD, because the majority of patients will not need an emergent procedure in a subsequent attack of $\mathrm{AD}$. There are not differences in the morbidity, mortality, and stoma rates between patients treated with nonoperative management and patients treated with elective surgery. A first episode of CAD is the only risk factor for emergency surgery in patients managed in a conservative form, and an elective colectomy must be considered in these patients. Further investigations focusing on patients with CAD are needed to identify ways to select patients capable of being managed conservatively.

\section{CONFLICT OF INTEREST}

No potential conflict of interest relevant to this article was reported.

\section{REFERENCES}

1. Floch MH, Bina I. The natural history of diverticulitis: fact and theory. J Clin Gastroenterol 2004;38(5 Suppl 1):S2-7.

2. Boles RS Jr, Jordan SM. The clinical significance of diverticulosis. Gastroenterology 1958;35:579-82.

3. Ambrosetti P, Grossholz M, Becker C, Terrier F, Morel P. Computed tomography in acute left colonic diverticulitis. Br J Surg 1997; 84:532-4.

4. Eglinton T, Nguyen T, Raniga S, Dixon L, Dobbs B, Frizelle FA.
Patterns of recurrence in patients with acute diverticulitis. $\mathrm{Br} \mathrm{J}$ Surg 2010;97:952-7.

5. Dharmarajan S, Hunt SR, Birnbaum EH, Fleshman JW, Mutch MG. The efficacy of nonoperative management of acute complicated diverticulitis. Dis Colon Rectum 2011;54:663-71.

6. Rafferty J, Shellito P, Hyman NH, Buie WD; Standards Committee of American Society of Colon and Rectal Surgeons. Practice parameters for sigmoid diverticulitis. Dis Colon Rectum 2006; 49:939-44.

7. Wong WD, Wexner SD, Lowry A, Vernava A 3rd, Burnstein M, Denstman F, et al. Practice parameters for the treatment of sigmoid diverticulitis: supporting documentation. The Standards Task Force. The American Society of Colon and Rectal Surgeons. Dis Colon Rectum 2000;43:290-7.

8. Haglund U, Hellberg R, Johnsen C, Hulten L. Complicated diverticular disease of the sigmoid colon. An analysis of short and long term outcome in 392 patients. Ann Chir Gynaecol 1979;68:41-6.

9. Guzzo J, Hyman N. Diverticulitis in young patients: is resection after a single attack always warranted? Dis Colon Rectum 2004; 47:1187-90.

10. Lopez-Borao J, Kreisler E, Millan M, Trenti L, Jaurrieta E, Rodriguez-Moranta F, et al. Impact of age on recurrence and severity of left colonic diverticulitis. Colorectal Dis 2012;14:e407-12.

11. Kaiser AM, Jiang JK, Lake JP, Ault G, Artinyan A, Gonzalez-Ruiz C, et al. The management of complicated diverticulitis and the role of computed tomography. Am J Gastroenterol 2005;100:910-7.

12. Hall JF, Roberts PL, Ricciardi R, Read T, Scheirey C, Wald C, et al. Long-term follow-up after an initial episode of diverticulitis: what are the predictors of recurrence? Dis Colon Rectum 2011;54:283-8.

13. Strate LL, Liu YL, Aldoori WH, Syngal S, Giovannucci EL. Obesity increases the risks of diverticulitis and diverticular bleeding. Gastroenterology 2009;136:115-122.e1.

14. Dobbins C, Defontgalland D, Duthie G, Wattchow DA. The relationship of obesity to the complications of diverticular disease. Colorectal Dis 2006;8:37-40.

15. Turunen P, Wikstrom H, Carpelan-Holmstrom M, Kairaluoma P, Kruuna O, Scheinin T. Smoking increases the incidence of complicated diverticular disease of the sigmoid colon. Scand J Surg 2010; 99:14-7.

16. Anaya DA, Flum DR. Risk of emergency colectomy and colostomy in patients with diverticular disease. Arch Surg 2005;140:681-5.

17. Ritz JP, Lehmann KS, Frericks B, Stroux A, Buhr HJ, Holmer C. Outcome of patients with acute sigmoid diverticulitis: multivariate analysis of risk factors for free perforation. Surgery 2011;149: 606-13.

18. Klarenbeek BR, Samuels M, van der Wal MA, van der Peet DL, Meijerink WJ, Cuesta MA. Indications for elective sigmoid resection in diverticular disease. Ann Surg 2010;251:670-4.

19. Franklin ME Jr, Dorman JP, Jacobs M, Plasencia G. Is laparoscopic surgery applicable to complicated colonic diverticular disease? Surg Endosc 1997;11:1021-5. 